ISSN 2503-2682 (Online)

ISSN 2503-3654 (Cetak)

\title{
Perencanaan Groundsill di Hilir Bendung Waikomo Kabupaten Lembata - NTT
}

\author{
Damianus Dai Tukan ${ }^{1}$, Suhudi ${ }^{2}$ \\ 1,2 Program Studi Teknik Sipil, Fakultas Teknik, Universitas Tribhuwana Tunggadewi - \\ Jl. Telaga Warna Blok C, Tlogomas, Malang 65144, Indonesia \\ e-mail: suhudi@unitri.ac.id
}

\begin{abstract}
ABSTRAK
Bendungan Waikomo di Kabupaten Lembata - Nusa Tenggara Timur digunakan untuk menaikkan ketinggian air Sungai Waikomo agar mengalir ke sawah seluas 1200 Ha. Panjang Weir $40 \mathrm{~m}$ dan tinggi $1,50 \mathrm{~m}$, terbuat dari beton. Kondisi bendungan Waikomo saat ini telah mencapai kedalaman hulu $1.0 \mathrm{~m}$ di hilir bendungan hingga $75 \mathrm{~m}$ lebih jauh ke hilir dan dinding penahan yang rusak di sepanjang sisi 7 $\mathrm{m}$. Tujuan penelitian ini untuk menentukan penyebab crush dan bagaimana dimensi bangunan pondasi digunakan untuk mengatasi penghancuran dan bagaimana stabilitas dasar direncanakan untuk menggulung, geser dan kapasitas bantalan. Fase penelitian ini meliputi observasi, pengukuran di lapangan dan mengumpulkan data sekunder dari instansi pemerintah. Setelah digunakan analisis penyebab gerusan di hilir bendung, analisis curah hujan, kemudian dilanjutkan dengan metode Log Pearson Type III. Setelah diketahui rencana debit periode kembali 50 tahun dari 39,999 m3 / dtk, begitu juga desain dari pengukuran landai dan menghitung stabilitas. Hasil penelitian menunjukkan bahwa penyebab himpitan bendung di hilir adalah karena penambangan bahan galian Waikomo C oleh masyarakat setempat. Tinggi rerumputan direncanakan $1 \mathrm{~m}$, panjang $30 \mathrm{~m}$, lebar 4,61 m, digunakan kolam penyerap energi tipe III dan terletak $75 \mathrm{~m}$ dari bendung Waikomo. Dari perhitungan diketahui bahwa rencana groundsill aman untuk menggulung, memindahkan dan daya dukung tanah dengan faktor keamanan $(\mathrm{SF})>1,5$.
\end{abstract}

Kata kunci : bendungan waikomo; analisa hidrologi; rencana groundsill; stabilitas

\begin{abstract}
Waikomo Dam in Lembata Regency - East Nusa Tenggara is used to raise the water level of the Waikomo River to flow to covering an rice fields area of $1200 \mathrm{Ha}$. Weir length of $40 \mathrm{~m}$ and height of $1.50 \mathrm{~m}$, made of concrete. The current condition of the Waikomo dam has reached the upstream depth of $1.0 \mathrm{~m}$ downstream of the dam up to $75 \mathrm{~m}$ further downstream and the damaged retaining wall along the $7 \mathrm{~m}$ side. The purpose of this study was to determine the cause of crush and how the dimensions of the foundation building were used to overcome the destruction and how the basic stability was planned for rolling, sliding and bearing capacity. This research phase includes observation, field measurements and collecting secondary data from government agencies. After using the analysis of the causes of scour downstream of the weir, rainfall analysis, then continued with the Log Pearson Type III method. After knowing the 50-year return period plan of $39,999 \mathrm{~m} 3$ / sec, so does the design of the ramps and calculating stability. The results showed that the cause of the downstream weir crush was due to mining of the Waikomo $C$ excavated material by the local community. The planned grass height is $1 \mathrm{~m}, 30 \mathrm{~m}$ long, $4.61 \mathrm{~m}$ wide, and is used for type III energy absorbing ponds and is located $75 \mathrm{~m}$ from the Waikomo dam. From the calculation it is known that the groundsill plan is safe for rolling, moving and carrying capacity of the land with a safety factor (SF) $>1.5$.
\end{abstract}

Keywords : waikomo weir; hydrological analysis; planning groundsill; stability 


\section{Pendahuluan}

Sungai adalah alur alamia yang mengalir menuju daerah yang lebih rendah dan merupakan sumber daya alam yang penting bagi manusia. Sungai Waikomo mempunyai panjang $\pm 6,252 \mathrm{~km}$ dan daerah pengaliran sebesar $1200 \mathrm{Ha}$ mengalir dari mata air di pegunungan Desa Namawekak kemudian mengalir ke utara melalui Desa Waikomo, Desa Pada dan Desa Waijarang yang kemudian bermuara di Pantai Lewoleba. Sungai Waikomo merupakan satu-satunya sungai yang dimanfaatkan masyarakat Kabupaten Lembata untuk irigasi. Sepanjang aliran Sungai Waikomo terdapat sebuah bangunan persungaian yaitu Bendung Waikomo yang dibangun pada tahun 1972.

Bendung adalah bangunan air yang berfungsi menaikkan elevasi muka air sungai guna mengalirkannya ke sawah melalui sistem irigasi. Bendung Waikomo yang dibahas pada penelitian ini terletak di Desa Waikomo Kelurahan Lewoleba Selatan, Kecamatan Nubatukan Kabupaten Lembata-NT'T.

Kondisi material dari hilir Bendung Waikomo berupa pasir berbatu. Kondisi di lapangan menunjukan adanya aktivitas penambangan pasir dan batu (galian C) oleh masyarakat setempat dari hilir bendung hingga ke hulu sungai.

Pengambilan pasir secara berlebihan dan tidak memperhatikan peraturan pemerintah mengenai syarat galian mengakibatkan terjadinya penurunan dasar sungai di beberapa tempat, salah satunya adalah di daerah hilir Bendung Waikomo. Penggerusan terjadi sepanjang $100 \mathrm{~m}$ ke arah hilir dari Bendung Waikomo sehingga menyebabkan bagian peredam (lantai lindung) pada bendung tersebut telah terjadi gerusan sedalam kurang lebih $1 \mathrm{~m}$, sedangkan dinding penahan bagian hilir runtuh sepanjang $7 \mathrm{~m}$.

Sejauh ini upaya dari pemerintah hanya sebatas menimbun lokasi gerusan dan membuat pondasi penahan sederhana di bagian hilir bendung. Upaya ini dilakukan hampir setiap tahunnya. Hal lain yang menyebabkan terjadinya permasalahan ini adalah masih rendahnya pemahaman masyarakat akan bahaya dari kegiatan penambangan pasir (galian C) terhadap keberadaan Bendung Waikomo. Jika kegiatan penambangan ini terus dibiarkan dapat menurunkan elevasi dasar sungai sehingga menyebabkan rembesan pada dasar bendung yang membuat menurunnya daya dukung tanah pada dasar bendung sehingga mengakibatkan bendung patah.

Tujuan penelitian ini adalah melakukan evaluasi permasalahan yang terjadi di lapangan dengan dilaksanakan perencanaan bangunan groundsill di bagian hilir Bendung Waikomo untuk mengatatasi penurunan elevasi dasar sungai sekaligus menjaga stabilitas Bendung Waikomo.

Secara geografis, Kabupaten Lembata berada pada gugusan Kepulauan Solor dan terletak di antara Kabupaten Flores Timur dan Kabupaten Alor dengan batas wilayah sebagai berikut:

Sebelah utara: Laut Flores

Sebelah selatan : Laut Sawu

Sebelah timur: Kabupaten Alor

Sebelah barat: Kabupaten Flores Timur. Secara astronomis Lembata terletak pada posisi $8^{\circ} 10^{\prime}-8^{\circ} 11^{\prime}$ LS dan $123^{\circ} 12^{\prime}-123^{\circ} 57^{\prime}$ BT. Iklim di Lembata tergolong kering dengan curah hujan rata-rata 001,95 $\mathrm{mm} /$ tahun atau $230 \mathrm{~mm}$ tertinggi pada Bulan Maret dan $14 \mathrm{~mm}$ terendah pada Bulan Mei. Suhu udara rata-rata $26-29{ }^{\circ} \mathrm{C}$ dengan suhu minimum dan maksimum berkisar antara $23-30{ }^{\circ} \mathrm{C}$. Kecepatan angin 
tergolong rendah rata-rata hanya 8,4 $\mathrm{knot} / \mathrm{jam}$.

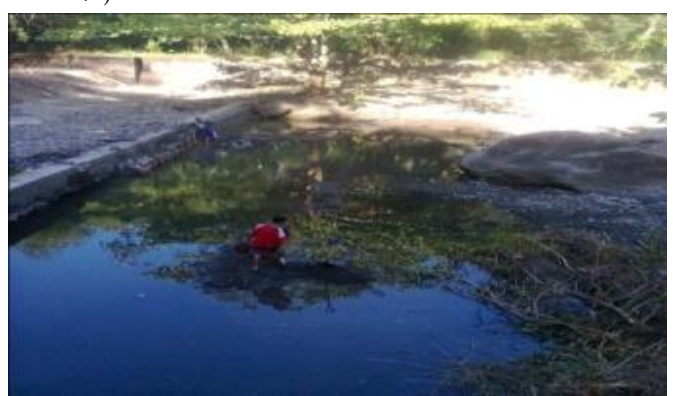

Gambar 1. Bagian hilir Bendung Waikomo

Hampir semua daerah pengaliran Sungai Waikomo adalah tanah-tanah pertanian yang subur menghasilkan berbagai macam hasil bumi diantaranya padi, jagung, kacang-kacangan, umbi-umbian dan tanaman lainnya.

Hasil survai yang dilakukan pada bulan Juni 2014 di lokasi, menunjukkan bahwa kondisi fisik Bendungan Waikomo telah terjadi penurunan dasar sungai sepanjang \pm $100 \mathrm{~m}$ di hilir bendung yang diakibatkan oleh adanya penambangan pasir oleh masyarakat setempat. Selain itu, dinding penahan bagian kanan di sebelah hilir bendung runtuh sepanjang $7 \mathrm{~m}$ dan terjadi penggerusan sedalam $\pm 1 \mathrm{~m}$ tepat pada bagian ujung hilir bendung yang menyebabkan retaknya lantai lindung.

Kondisi tersebut dikhawatirkan akan adanya aliran air di bawah bendung yang akan mengakibatkan bertambah dalamnya palung di hilir bendung sehingga daya dukung tanah berkurang dan dapat menyebabkan bendung patah. Selain itu, kegiatan penambangan pasir oleh masyarakat yang tidak mengikuti aturan dapat merusak morfologi sungai dan membahayakan keberadaan Bendung Waikomo. Sehingga perlu tindakan terpadu dan terkoordinasi guna mewujudkan penangan masalah secara optimal.

\section{Metode Penelitian}

\section{a. Rencana pemecahan masalah}

Dimensi rencana groundsill untuk mengatasi masalah dalam perhitungannya menggunakan data-data yang diperoleh dari instansi-instansi pemerintah (data sekunder) serta data hasil survai (data primer). Dengan asumsi bahwa data-data tersebut dianggap benar dan dapat digunakan dalam perhitungan.

b. Data perencanaan

Data debit

Data debit yang digunakan adalah data debit maksimum tahunan Sungai Waikomo dari tahun 1992 sampai 2013. Data ini diperoleh dari Dinas Pekerjaan Umum Kabupaten Lembata.

Data tanah

Data tanah (daya dukung tanah), digunakan dalam perhitungan stabilitas groundsill. Data tanah diperoleh dari Dinas Pekerjaan Umum Kabupaten Lembata.

Peta topografi

Untuk mengetahui letak atau posisi groundsill rencana, digunakan peta Bakosurtanal dengan skala $1: 25.000$. Selain itu digunakan juga peta geografi Kabupaten Lembata serta peta kontur dari google eart.

Data teknis

Data teknis ini diperoleh dari hasil pengamatan dan pengukuran di lapangan diantaranya denah dan potongan bendung.

c. Langkah penyelesaian

Setelah data tersebut di atas dikumpulkan, selanjutnya dilakukan perhitungan sebagai berikut : 
- Data curah hujan maksimum tahunan diolah menggunakan distribusi Log Pearson Tipe III untuk mendapatkan debit maksimum sungai dengan kala ulang tertentu.

- Menentukan letak dan posisi groundsill rencana sesuai peta Bakosurtanal. Dalam hal ini adalah untuk mengetahui lebar groundsill dan kemiringan sungai.

- Merencanakan dimensi groundsill.

- Analisa stabilitas groundsill terhadap guling, geser dan daya dukung tanah.

\section{Hasil dan Pembahasan}

a. Analisa debit banjir rancangan

Debit banjir rancangan adalah debit banjir terbesar tahunan dengan suatu kemungkinan terjadi yang tertentu.

Tabel 1. Debit banjir harian maksimum.

\begin{tabular}{c|c|c}
\hline No & Tahun & Debit $\left(\mathrm{m}^{3} / \mathrm{dtk}\right)$ \\
\hline 1 & 1998 & 33,5 \\
\hline 2 & 1999 & 32,0 \\
\hline 3 & 2000 & 33,0 \\
\hline 4 & 2001 & 32,0 \\
\hline 5 & 2002 & 29,0 \\
\hline 6 & 2003 & 27,0 \\
\hline 7 & 2004 & 24,0 \\
\hline 8 & 2005 & 34,0 \\
\hline 9 & 2006 & 33,0 \\
\hline 10 & 2007 & 34,5 \\
\hline 11 & 2008 & 23,5 \\
\hline 12 & 2009 & 20,0 \\
\hline 13 & 2010 & 32,5 \\
\hline 14 & 2011 & 22,0 \\
\hline 15 & 2012 & 20,5 \\
\hline
\end{tabular}

Metode perhitungan pendekatan yang digunakan dalam perencanaan ini adalah metode Log Pearson Type III.

- Data debit banjir harian maksimum tahunan sebanyak " $n$ " tahun diubah dalam bentuk logaritma.

- Hitung rata-rata logaritma dengan rumus

$$
\begin{aligned}
& \overline{\log Q}=\frac{\sum_{i=1}^{n} Q i}{n} \\
& \overline{\log Q}=\frac{\mathbf{2 2 , 1 2 4 5}}{15}=1,475
\end{aligned}
$$

- Hitung simpangan baku dengan rumus:

$$
\begin{aligned}
& S=\sqrt{\frac{\sum(\log Q i-\log Q)^{2}}{n-1}} \\
& S=\sqrt{\frac{0,05503264}{15-1}} \\
& S=0,062696911
\end{aligned}
$$

- Hitung koefisien kepencengan dengan rumus:

$$
\begin{aligned}
& C s=\frac{\sum_{i=1}^{n}(\log Q i-\log Q)^{3}}{(n-1)(n-2) s^{3}} \\
& C s=\frac{-0,00232620}{(15-1)(15-2) s^{3}} \\
& C s=\frac{-0,00232620}{(14)(13) 0,062696911^{3}} \\
& C s=-0,0519
\end{aligned}
$$

- Hitung logaritma debit banjir rancangan dengan rumus:

$$
\begin{aligned}
& \left.\log \mathrm{Q}_{\mathrm{T}}=\overline{\log Q}+\text { G.S }\right) \\
& \log \mathrm{Q}_{\mathrm{T}}=1,475+\text { G . 0,062696911 }
\end{aligned}
$$

Dari perhitungan sebelumnya dengan nilai Cs $=-0,0519$ dengan cara interpolasi didapat $G=2,025$

$$
\begin{aligned}
& \log Q_{T}=1,475+2,025.0,0626969 \\
& \log Q_{T}=1,602 \\
& Q_{T}=39,999 \mathrm{~m}^{3} / \text { dtk. }
\end{aligned}
$$

\section{b. Pendimensian Groundsill}

Bangunan groundsill direncanakan $75 \mathrm{~m}$ di sebelah hilir Bendung Waikomo dengan lebar dasar sungai $30 \mathrm{~m}$. Berdasarkan hasil analisa debit banjir rancangan kala ulang 50 tahun, diperoleh debit banjir rancangan sebesar $39,999 \mathrm{~m}^{3} / \mathrm{dtk}$.

\section{Menentukan tinggi muka air di atas Groundsill.}

Perhitungan tinggi muka air di atas groundsill menggunakan persamaan sebagai berikut: 


$$
\mathrm{Q}=\mathrm{C} \cdot \mathrm{b} \cdot \mathrm{H}_{0}^{3 / 2}
$$

Direncanakan tinggi groundsill $(\mathrm{P})=1 \mathrm{~m}$

Debit per satuan lebar (q) :

$$
\mathrm{q}=\frac{Q}{b}=\frac{39,999}{30}=1,333 \mathrm{~m}^{3} / \mathrm{dtk} / \mathrm{m}^{1}
$$

Menentukan koefisien limpahan (C)

Untuk harga $\mathrm{C}$ mula-mula

direncanakan $=2,10$ maka :

$$
\begin{aligned}
& \mathrm{Hd}=\left(\frac{\mathrm{Q}}{\mathrm{C} \times \mathrm{b}}\right)^{2 / 3} \\
& \mathrm{Hd}=\left(\frac{39,999}{2,1 \times 30}\right)^{2 / 3}=0,739 \mathrm{~m}
\end{aligned}
$$

Pada saat $\mathrm{h}=\mathrm{Hd}$ dan $\mathrm{C}=\mathrm{Cd}$,maka :

$$
\begin{aligned}
\mathrm{C} & =2\left\lfloor\frac{1+2 a\left(\frac{h}{h d}\right)}{1+a\left(\frac{h}{h d}\right)}\right\rfloor \\
\mathrm{C} & =1,6\left[\frac{1+2 a\left(\frac{h}{h d}\right)}{1+a\left(\frac{h}{h d}\right)}\right\rfloor \\
\mathrm{Cd} & =2,20-0,0416\left(\frac{H d}{w}\right)^{0,990} \\
a & =\frac{0,6-\left[0,0416\left(\frac{H d}{w}\right)^{0,990}\right]}{1+\left[0,0416\left(\frac{H d}{w}\right)^{0,990}\right]} \\
& =\frac{0,6-\left[0,0416\left(\frac{0,739}{1}\right)^{0,990}\right]}{1+\left[0,0416\left(\frac{0,739}{1}\right)^{0,990}\right]} \\
& =0,569
\end{aligned}
$$

Sedangkan harga $\mathrm{C}$ pada saat $\mathrm{h}=\mathrm{Hd}$ :

$$
\begin{aligned}
& C=1,6 \times\left[\frac{1+\left[2 \times 0,569\left(\frac{0,739}{0,739}\right)\right]}{1+\left[0.569\left(\frac{0,739}{0,739}\right)\right]}\right] \\
& =2,18
\end{aligned}
$$

Harga C rencana tidak sama dengan C hitung, maka selanjutnya direncanakan lagi harga $C$ yang lain sampai diperoleh angka $C$ hitung sama dengan $\mathrm{C}$ rencana. Perhitungan selanjutnya ditabelkan pada Tabel 2.

Tabel 2. Perhitungan harga koefisien limpahan $(C)$

\begin{tabular}{c|c|c|c}
\hline $\mathrm{C}_{\text {Rencana }}$ & $\mathrm{Hd}$ & $\mathrm{a}$ & $\mathrm{C}_{\text {Htung }}$ \\
\hline 2,10 & 0,739 & 0,569 & 2.18 \\
\hline 2.18 & 0,612 & 0,570 & 2,18 \\
\hline
\end{tabular}

Sumber: Hasil perbitungan.
Mencari Harga $h_{0}$ :

$$
\begin{aligned}
& \mathrm{q}=1,333 \mathrm{~m}^{3} / \mathrm{dtk} / \mathrm{m}^{1} \\
& \mathrm{H}_{0}=(\mathrm{q} / \mathrm{C})^{2 / 3} \\
& =(1,333 / 2.18)^{2 / 3}=0,719 \mathrm{~m} \\
& \mathrm{Q}=\mathrm{A} \times \mathrm{maka} \mathrm{V}=\mathrm{Q} / \mathrm{A} \\
& \mathrm{Q}=\mathrm{C} \cdot \mathrm{b} \cdot \mathrm{H}_{0}^{2 / 3}
\end{aligned}
$$

Dimana $: \mathrm{q}=\mathrm{Q} / \mathrm{b}_{\text {eff }}, \mathrm{A}=\mathrm{b} \cdot\left(\mathrm{P}+\mathrm{H}_{0}\right)$ dan $\mathrm{V}$ $=\frac{q}{P+h_{0}}$

Sehingga persamaan menjadi :

$$
\begin{array}{ll}
\mathrm{H}_{0} & =\mathrm{h}_{0}+\mathrm{h}_{\mathrm{a}} \\
\mathrm{H}_{0} & =\mathrm{h}_{0}+\frac{V^{2}}{2 q} \\
\mathrm{H}_{0} & =\mathrm{h}_{0}+\frac{\left(\frac{q}{P+h_{0}}\right)^{2}}{2 g} \\
& =\mathrm{h}_{0}+\frac{q^{2}}{2 g(P+h o)^{2}} \\
0,719 & =\mathrm{h}_{0}+\frac{1,333^{2}}{2.9,81(1+h o)^{2}}
\end{array}
$$

Dengan cara Trial an Error diperoleh $\mathrm{h}_{0}=$ 0,688 m.

Maka ha $=0,719-0,688$

$$
=0,031 \mathrm{~m}
$$

\section{Perbitungan bentuk Groundsill}

Bentuk lengkung bagian bilir

$\mathrm{Y}=-\mathrm{k} \cdot \mathrm{H}_{0} \cdot \frac{X^{n}}{H_{0}^{n}}$

$\frac{Y}{H_{0}}=-k\left[\frac{X}{H_{0}}\right]^{n}$

$\frac{h_{a}}{H_{0}}=\frac{0,031}{0,719}=0,043$

Dengan menggunakan grafik dengan ha/ho $=0,106$ maka diperoleh $\mathrm{k}=0,507$ dan $\mathrm{n}=$ 1,83

$$
\text { Maka } \begin{aligned}
\frac{Y}{0,719} & =-0,507\left(\frac{X}{0,719}\right)^{1,83} \\
Y & =-0,365\left(\frac{X}{0,719}\right)^{1,83}
\end{aligned}
$$

Koordinat titik singgung

Kemiringan di hilir direncanakan 1:1 maka garis singgung pada persamaan lengkung $Y=-0,365\left(\frac{X}{0,719}\right)^{1,83}$ adalah sebagai berikut : 


$$
\frac{d y}{d x}=\operatorname{tg} \alpha=\operatorname{tg} 45^{\circ}=(-1)
$$

karena masuk kuadran IV maka nilai tangen $(-)$

$$
\begin{aligned}
& \quad-\frac{d y}{d x}=-k \cdot H_{0} \cdot n \frac{X^{n-1}}{H_{0}^{n}} \\
& -\frac{d y}{d x} \\
& =-0,507 \cdot 0,719 \cdot 1,83 \frac{X^{1,83-1}}{0,719^{1,83}} \\
& -\quad \frac{d y}{d x}=1,2 \mathrm{X}^{0,835}
\end{aligned}
$$

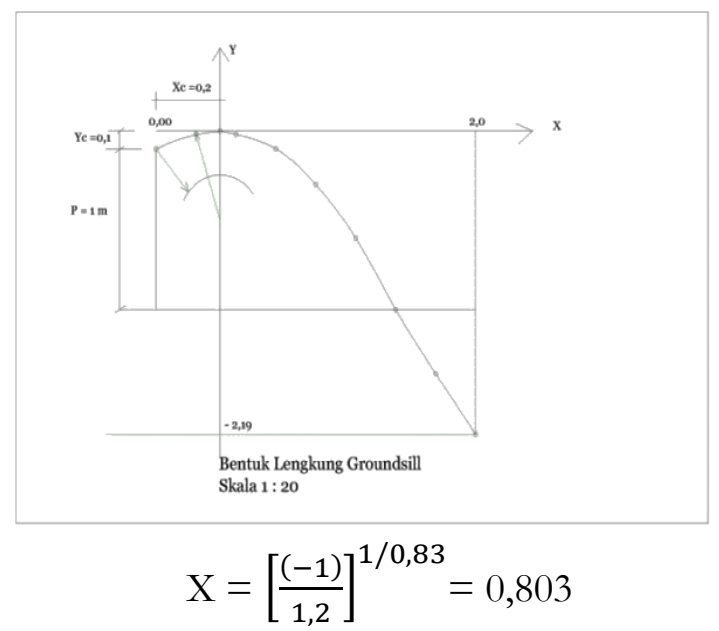

Gambar 2. Bentuk lengkung Graundsill

$$
Y=-0,365\left(\frac{0,803}{0,719}\right)^{1,83}=-0,445 \mathrm{~m}
$$

Tabel 3. Koordinat titik lengkung Groundsill pada bagian hilir

\begin{tabular}{c|c|c}
\hline Titik & $\mathbf{X}(\mathbf{m})$ & $\mathbf{Y}(\mathbf{m})$ \\
\hline 0 & 0,0 & 0,00 \\
\hline 1 & 0,10 & 0,001 \\
\hline 2 & 0,20 & 0,035 \\
\hline 3 & 0,30 & 0,074 \\
\hline 4 & 0,40 & 0,125 \\
\hline 5 & 0,50 & 0,188 \\
\hline 6 & 0,60 & 0,262 \\
\hline 7 & 0,70 & 0,347 \\
\hline 8 & 0,80 & 0,445 \\
\hline
\end{tabular}

Bentuk lengkung bagian bulu
Bentuk lengkung groundsill atau mercu direncanakan dengan memakai lengkung type ogge dengan muka bagian hulu vertikal.

$$
\frac{h_{a}}{H_{0}}=\frac{0,031}{0,719}=0,043
$$

Dengan menggunakan grafik tentang bentuk lengkung depan hulu dengan

$$
\frac{h_{a}}{H_{0}}=\frac{0,031}{0,719}=0,043
$$

maka didapat :

$$
\begin{aligned}
& \frac{X_{c}}{H_{0}}=0,263 \rightarrow \mathrm{X}_{\mathrm{c}} \\
& =0,263 \times 0,719=0,189 \approx 0,19 \mathrm{~m} \\
& \frac{Y_{c}}{H_{0}}=0,1675 \rightarrow \mathrm{Y}_{\mathrm{c}} \\
& =0,1675 \times 0,719=0,1204 \approx 0,12 \mathrm{~m} \\
& \frac{R_{1}}{H_{0}}=0,51 \rightarrow \mathrm{R}_{1} \\
& =0,51 \times 0,719=0,366 \approx 0,37 \mathrm{~m} \\
& \frac{R_{2}}{H_{0}}=0,21 \rightarrow \mathrm{R}_{2} \\
& =0,21 \times 0,719=0,1501 \approx 0,15 \mathrm{~m}
\end{aligned}
$$

\section{c. Perencanaan peredam energi}

Sebelum aliran yang melintasi bangunan groundsill dikembalikan lagi ke sungai, maka aliran dalam kecepatan yang tinggi dalam kondisi super kritis tersebut harus diubah menjadi sub kritis dengan menggunakan bangunan peredam energi tipe kolam olakan.

\section{- Pemiliban tipe kolam olakan}

Berdasarkan hasil analisa tinggi muka air diatas mercu groundsill didapat data-data sebagai berikut:

$\mathrm{P}=1,0 \mathrm{~m} ; \mathrm{h}_{0}=0,688 \mathrm{~m} ; \mathrm{h}_{\mathrm{a}}=0,031$ debit per satuan lebar $=1,333 \mathrm{~m}^{3} / \mathrm{dtk} / \mathrm{m}^{1}$ Persamaan garis energi:

$$
\begin{aligned}
& \mathrm{z}_{0}+\mathrm{P}+\mathrm{h}_{0}+\mathrm{h}_{\mathrm{a}}=\mathrm{y}_{1}+\frac{v_{1}^{2}}{2 . g} \\
& \mathrm{~V}_{1}=\frac{Q}{b \cdot y_{1}}
\end{aligned}
$$

Sehingga :

$$
\begin{aligned}
& \mathrm{z}_{0}+\mathrm{P}+\mathrm{h}_{0}+\mathrm{h}_{\mathrm{a}}=\mathrm{y}_{1}+\frac{\left(\frac{Q}{b}\right)^{2}}{2 \cdot g\left(y_{1}\right)^{2}} \\
& 0+1,0+0,688+0,031
\end{aligned}
$$




$$
=\mathrm{y}_{1}+\frac{\left(\frac{39,999}{30}\right)^{2}}{2.9,81\left(y_{1}\right)^{2}}
$$

Dengan cara trial and error diperoleh

$\mathrm{y}_{1}=0,2496 \mathrm{~m}$.

$\mathrm{V}_{1}=\frac{q}{y_{1}}=\frac{1,333}{0,2496}=5,341 \mathrm{~m} / \mathrm{dtk}$

\section{- Bilangan Froude}

$\operatorname{Fr}=\frac{V_{1}}{\sqrt{g \times Y_{1}}}=\frac{5,341}{\sqrt{9,81 \times 0,2496}}=3,413$

Sesuai dengan tekanan hidrostatis rendah dan debit yang agak kecil $(\mathrm{q}<18,5$ $\mathrm{m}^{3} / \mathrm{dtk} / \mathrm{m}$, kecepatan $\mathrm{V}<18 \mathrm{~m} / \mathrm{dtk}$ maka dipakai kolam olakan tipe III.

Dari perhitungan sebelumnya didapat nilai $\mathrm{y}_{1}=\mathrm{d}_{1}=0,2496 \mathrm{~m}$ dan dengan menggunakan grafik, nilai $\mathrm{Fr}=3,413$, maka kedalaman air di hilir peredam energi $\left(d_{2}=\right.$ $\mathrm{y}_{2}$ ) dihitung dengan persamaan berikut:

$$
\begin{aligned}
& \frac{d_{2}}{d_{1}}=\frac{1}{2}\left(\sqrt{\left(1+8 \cdot F r^{2}\right)-1}\right) \\
& \mathrm{d}_{2}=\frac{1}{2} \times 0,2496\left(\sqrt{\left(8 \times 3,413^{2}\right)-1}\right) \\
& =1,199 \mathrm{~m} \\
& \quad \text { Menghitung } \mathrm{H}_{\mathrm{T}}=\left(\mathrm{P}+\mathrm{h}_{0}\right)-\mathrm{y}_{2}=(1,00 \\
& \quad+0,688)-1,199=0,489 \mathrm{~m} .
\end{aligned}
$$

- Perbitungan dimensi kolam olakan

Dimensi gigi pemencar aliran (chute blocks).

- Tinggi gigi pemencar aliran $\quad: \quad \mathrm{h}_{1}$ $=\mathrm{d}_{1}=0,2496 \mathrm{~m}=0,25 \mathrm{~m}$

- Lebar gigi pemencar aliran : $\quad \mathrm{w}_{1}$ $=\mathrm{d}_{1}=0,25 \mathrm{~m}$

- Panjang gigi pemencar aliran : $\mathrm{t}_{1}=\mathrm{d}_{1}=0,25 \mathrm{~m}$

- Jarak gigi pemencar $\quad: \mathrm{s}_{1}=\mathrm{d}_{1}=$ $0,25 \mathrm{~m}$

Gigi benturan (buffle blocks).

Dengan menggunakan bilangan froude $=$ 3,413 diperoleh $h_{3} / h_{1}=1,3$ maka:

- Tinggi gigi benturan $=\mathrm{h}_{3}=1,3 \times \mathrm{d}_{1}=0,325=0,35 \mathrm{~m}$

- Tebal puncak gigi benturan $=\mathrm{t}_{2}=0,2 \times \mathrm{h} 3=0,05=0,05 \mathrm{~m}$
- Lebar gigi benturan $=\mathrm{W}_{3}=0,75 \times \mathrm{h}_{3}=0,2625=0,3 \mathrm{~m}$

- Jarak antara gigi benturan $=\mathrm{S}_{3}=0,75 \times \mathrm{h}_{3}=0,2625=0,3 \mathrm{~m}$

- Jarak antara gigi benturan dengan gigi pemencar

$$
=0,8 \mathrm{~d}_{2}=0,9592=1,0 \mathrm{~m} \text {. }
$$

Ambang perata Aliran (End Sill).

Dengan menggunakan grafik penentuan kolam olakan tipe III dengan $\mathrm{Fr}=3,413$ maka harga $\mathrm{d}_{4} / \mathrm{d}_{1}=1,16$

- Tinggi ambang perata aliran

$$
=\mathrm{h}_{4}=1,16 \times \mathrm{d}_{1}=0,289=0,25 \mathrm{~m}
$$

- Tebal puncak ambang perata

$$
=\mathrm{t}_{3}=0,2 \times \mathrm{h}_{4}=0,06 \mathrm{~m}=0,10 \mathrm{~m}
$$

Panjang lantai peredam energi.

Dengan grafik length of jump dengan bilangan froude 2,473 maka $\mathrm{L} / \mathrm{d}_{2}=1,9$ maka

$$
\mathrm{L}=1,9 \times 1,199=2,2781=2,3 \mathrm{~m}
$$

\section{- Kontrol panjang rayapan}

Perhitungan panjang rayapan aliran menggunakan teori Lane sebagai berikut: $L c$ $\geq$ Hmaks $\times c$.

Besarnya nilai Creep Line (C) dapat dijelaskan bahwa untuk material pasir halus $=4,0$ dan dengan tinggi groundsill $=1,0 \mathrm{~m}$, maka :

$\mathrm{H}_{\max } \times \mathrm{C}=4,97 \mathrm{~m}$ sehingga $: \mathrm{Lc}=4,97 \mathrm{~m}$ $\geq \mathrm{H}_{\max } \mathrm{c}=4,0 \rightarrow$ aman.

\section{- Kontrol tebal lantai kolam olakan}

Penentuan tebal kolam olakan harus dikontrol agar mampu menahan gaya tekanan angkat (uplift pressure) dari aliran saat terjadi banjir. Uplift dihitung pada titik kritis yaitu ujung lantai kolam olakan.

a. Menghitung tekanan uplift (UP).

$$
\mathrm{UP}=\left[\frac{L-L f}{L}\right] \Delta H \cdot \gamma_{w}
$$

Dengan nilai berat jenis air $\left(\gamma_{w}\right)=1,0$ ton $/ \mathrm{m}^{3}$, dan nilai berat jenis beton 
$\left(\gamma_{\text {beton }}\right)=2,4$ ton $/ \mathrm{m}^{3}$, maka besarnya tekanan angkat (uplift pressure) adalah :

$$
\begin{aligned}
& \mathrm{UP}=\left[\frac{L-L f}{L}\right] \Delta H \cdot \gamma_{w} \\
& \mathrm{UP}=\left[\frac{4,97-3,51}{4,97}\right] 1,469 \times \cdot 1 \\
& =0,432 \mathrm{ton} / \mathrm{m}^{3}
\end{aligned}
$$

b. Tebal lantai (d).

$$
\begin{aligned}
& \mathrm{d}=\frac{4}{3} \cdot \frac{U P}{\gamma_{\text {beton }+} \gamma_{w}}=\frac{4}{3} \times \frac{0,432}{3,4} \\
& =0,169<\mathrm{d} \text { rencana }=0,5 \mathrm{~m} \rightarrow \text { aman }
\end{aligned}
$$

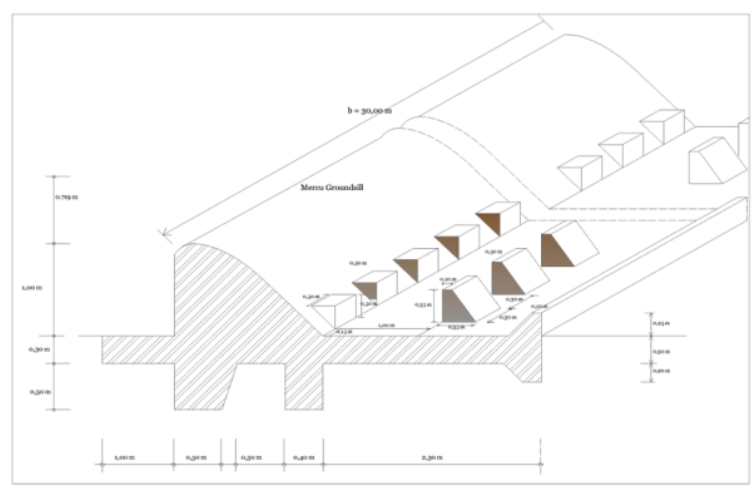

Gambar 3. Detail kolam olakan

\section{d. Stabilitas Groundsill}

Suatu konstruksi dikatakan stabil apabila konstruksi tersebut mampu menahan semua beban yang bekerja. Dalam analisa stabilitas groundsill ini, kontrol stabilitas yang diperhitungkan adalah guling, geser dan daya dukung tanah.

Gaya-gaya yang bekerja pada tubuh groundsill adalah:

1. Gaya Uplift pressure.

2. Gaya hidrostatis.

3. Gaya berat air.

4. Gaya berat sedimen.

5. Gaya hidrodinamis karena gempa.

6. Gaya tekan sedimen.

7. Gaya tekanan hiidrostatis.

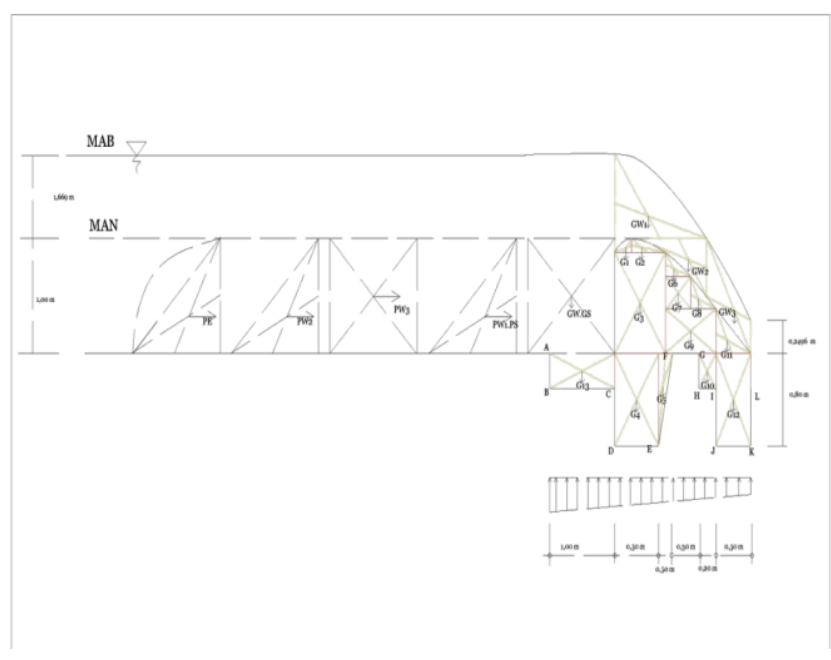

Gambar 4. Gaya yang bekerja pada tubuh Groundsill

1. Stabilitas terbadap guling

- Kondisi air normal.

Tanpa Gempa.

$\mathrm{SF}=\frac{M_{r}}{M_{o}} \geq 1,5$

$\mathrm{SF}=\frac{19,178}{1,093}=17,5461,5($ aman $)$

Dengan Gempa.

$\mathrm{SF}=\frac{M_{r}}{M_{o}} \geq 1,2$

$\mathrm{SF}=\frac{18,415}{1,666}=11,053 \geq 1,2($ aman $)$

- Kondisi air banjir.

Tanpa Gempa.

$\mathrm{SF}=\frac{M_{r}}{M_{o}} \geq 1,5$

$\mathrm{SF}=\frac{16,791}{2,027}=8,283 \geq 1,5($ aman $)$

Dengan Gempa.

$\mathrm{SF}=\frac{M_{r}}{M_{o}} \geq 1,2$

$\mathrm{SF}=\frac{17,028}{2,60}=6,549 \geq 1,2($ aman $)$ 
Tabel 4. Gaya yang bekerja pada tubuh groundsill pada kondisi air normal

\begin{tabular}{|c|c|c|c|c|c|c|c|}
\hline \multicolumn{4}{|c|}{ Tanpa Gempa } & \multicolumn{4}{|c|}{ Dengan Gempa } \\
\hline \multicolumn{2}{|c|}{ Gaya Vertikal (ton) } & \multicolumn{2}{|c|}{ Gaya Horisontal (ton) } & \multicolumn{2}{|c|}{ Gaya Vertikal (ton) } & \multicolumn{2}{|c|}{ Gaya Horisontal (ton) } \\
\hline $\begin{array}{l}\text { Gaya berat } \\
\text { groundsill }\end{array}$ & 6,51 & Gaya hidrostatis & 0,5 & $\begin{array}{l}\text { Gaya berat } \\
\text { groundsill }\end{array}$ & 6,51 & Gaya hidrostatis & 0,5 \\
\hline $\begin{array}{l}\text { Gaya uplift } \\
\text { pressure }\end{array}$ & $-3,226$ & $\begin{array}{l}\text { Gaya tekan } \\
\text { sedimen }\end{array}$ & 0,476 & $\begin{array}{l}\text { Gaya uplift } \\
\text { pressure }\end{array}$ & $-3,226$ & $\begin{array}{l}\text { Gaya } \\
\text { hidrodinamis }\end{array}$ & 0,051 \\
\hline Gaya berat air & 1,0 & & & Gaya berat air & 1,00 & $\begin{array}{l}\text { Gaya tekan } \\
\text { sedimen }\end{array}$ & 0,476 \\
\hline $\begin{array}{l}\text { Gaya berat } \\
\text { sedimen }\end{array}$ & 1,70 & & & $\begin{array}{l}\text { Gaya berat } \\
\text { sedimen }\end{array}$ & 1,70 & $\begin{array}{l}\text { Gempa } \\
\text { horizontal }\end{array}$ & 0,2333 \\
\hline & & & & Gempa vertikal & 0,1977 & & \\
\hline$\Sigma \mathrm{V}$ & 5,984 & $\boldsymbol{\Sigma} \mathrm{H}$ & 0,976 & $\Sigma \mathrm{V}$ & 6,182 & $\boldsymbol{\Sigma} \mathrm{H}$ & 1,26 \\
\hline
\end{tabular}

Tabel 5. Gaya yang bekerja pada tubuh groundsill pada kondisi air banjir

\begin{tabular}{|c|c|c|c|c|c|c|c|}
\hline \multicolumn{4}{|c|}{ Tanpa Gempa } & \multicolumn{4}{|c|}{ Dengan Gempa } \\
\hline \multicolumn{2}{|c|}{ Gaya Vertikal (ton) } & \multicolumn{2}{|c|}{ Gaya Horisontal (ton) } & \multicolumn{2}{|c|}{ Gaya Vertikal (ton) } & \multicolumn{2}{|c|}{ Gaya Horisontal (ton) } \\
\hline $\begin{array}{l}\text { Gaya berat } \\
\text { groundsill }\end{array}$ & 6,51 & Gaya hidrostatis & 1,219 & $\begin{array}{l}\text { Gaya berat } \\
\text { groundsill }\end{array}$ & 6,51 & Gaya hidrostatis & 1,219 \\
\hline $\begin{array}{l}\text { Gaya uplift } \\
\text { pressure }\end{array}$ & $-3,525$ & $\begin{array}{l}\text { Gaya tekan } \\
\text { sedimen }\end{array}$ & 0,476 & $\begin{array}{l}\text { Gaya uplift } \\
\text { pressure }\end{array}$ & $-3,525$ & $\begin{array}{l}\text { Gaya } \\
\text { hidrodinamis }\end{array}$ & 0,051 \\
\hline Gaya berat air & 2,516 & & & Gaya berat air & 2,516 & $\begin{array}{l}\text { Gaya tekan } \\
\text { sedimen }\end{array}$ & 0,476 \\
\hline \multirow[t]{2}{*}{$\begin{array}{l}\text { Gaya berat } \\
\text { sedimen }\end{array}$} & 1,70 & & & $\begin{array}{l}\text { Gaya berat } \\
\text { sedimen }\end{array}$ & 1,70 & $\begin{array}{l}\text { Gempa } \\
\text { horizontal }\end{array}$ & 0,2333 \\
\hline & & & & Gempa vertikal & 0,1977 & & \\
\hline $\boldsymbol{\Sigma} \mathrm{V}$ & 7,201 & $\boldsymbol{\Sigma} \mathrm{H}$ & 1,695 & $\boldsymbol{\Sigma} \mathrm{V}$ & 7,399 & $\boldsymbol{\Sigma} \mathrm{H}$ & 1,979 \\
\hline
\end{tabular}

Tabel 6. Momen yang terjadi akibat gaya yang bekerja pada kondisi air normal

\begin{tabular}{|c|c|c|c|c|c|c|c|}
\hline \multicolumn{4}{|c|}{ Tanpa Gempa } & \multicolumn{4}{|c|}{ Dengan Gempa } \\
\hline \multicolumn{2}{|c|}{$\begin{array}{c}\text { Momen Tahanan(Mr) } \\
\text { (ton.m) }\end{array}$} & \multicolumn{2}{|c|}{$\begin{array}{l}\text { Momen Guling (Mo) } \\
\text { (ton.m) }\end{array}$} & \multicolumn{2}{|c|}{$\begin{array}{c}\text { Momen Tahanan(Mr) } \\
\text { (ton.m) }\end{array}$} & \multicolumn{2}{|c|}{$\begin{array}{l}\text { Momen Guling (Mo) } \\
\text { (ton.m) }\end{array}$} \\
\hline $\begin{array}{l}\text { Gaya berat } \\
\text { groundsill }\end{array}$ & 7,894 & $\begin{array}{l}\text { Gaya } \\
\text { hidrostatis }\end{array}$ & 0,56 & $\begin{array}{l}\text { Gaya berat } \\
\text { groundsill }\end{array}$ & 7,894 & $\begin{array}{l}\text { Gaya } \\
\text { hidrostatis }\end{array}$ & 0,56 \\
\hline $\begin{array}{l}\text { Gaya uplift } \\
\text { pressure }\end{array}$ & $-4,546$ & $\begin{array}{l}\text { Gaya tekan } \\
\text { sedimen }\end{array}$ & 0,533 & $\begin{array}{l}\text { Gaya uplift } \\
\text { pressure }\end{array}$ & $-5,546$ & $\begin{array}{l}\text { Gaya } \\
\text { hidrodinamis }\end{array}$ & 0,058 \\
\hline Gaya berat air & 5,82 & & & Gaya berat air & 5,82 & $\begin{array}{l}\text { Gaya tekan } \\
\text { sedimen }\end{array}$ & 0,533 \\
\hline \multirow[t]{2}{*}{$\begin{array}{l}\text { Gaya berat } \\
\text { sedimen }\end{array}$} & 10,01 & & & $\begin{array}{l}\text { Gaya berat } \\
\text { sedimen }\end{array}$ & 10,01 & $\begin{array}{l}\text { Gempa } \\
\text { horizontal }\end{array}$ & 0,515 \\
\hline & & & & Gempa vertikal & 0,237 & & \\
\hline $\boldsymbol{\Sigma} \mathrm{V}$ & 19,178 & $\boldsymbol{\Sigma} \mathrm{H}$ & 1,093 & $\Sigma \mathrm{V}$ & 18,415 & $\boldsymbol{\Sigma} \mathrm{H}$ & 1,666 \\
\hline
\end{tabular}

Tabel 7. Momen yang terjadi akibat gaya yang bekerja pada kondisi air banjir

\begin{tabular}{|c|c|c|c|c|c|c|c|}
\hline \multicolumn{4}{|c|}{ Tanpa Gempa } & \multicolumn{4}{|c|}{ Dengan Gempa } \\
\hline \multicolumn{2}{|c|}{$\begin{array}{l}\text { Momen Tahanan(Mr) } \\
\text { (ton.m) }\end{array}$} & \multicolumn{2}{|c|}{$\begin{array}{l}\text { Momen Guling (Mo) } \\
\text { (ton.m) }\end{array}$} & \multicolumn{2}{|c|}{$\begin{array}{l}\text { Momen Tahanan(Mr) } \\
\text { (ton.m) }\end{array}$} & \multicolumn{2}{|c|}{$\begin{array}{l}\text { Momen Guling (Mo) } \\
\text { (ton.m) }\end{array}$} \\
\hline $\begin{array}{l}\text { Gaya berat } \\
\text { groundsill }\end{array}$ & 7,894 & $\begin{array}{l}\text { Gaya } \\
\text { hidrostatis }\end{array}$ & 1,494 & $\begin{array}{l}\text { Gaya berat } \\
\text { groundsill }\end{array}$ & 7,894 & Gaya hidrostatis & 1,494 \\
\hline $\begin{array}{l}\text { Gaya uplift } \\
\text { pressure }\end{array}$ & $-5,088$ & $\begin{array}{l}\text { Gaya tekan } \\
\text { sedimen }\end{array}$ & 0,533 & $\begin{array}{l}\text { Gaya uplift } \\
\text { pressure }\end{array}$ & $-5,088$ & $\begin{array}{l}\text { Gaya } \\
\text { hidrodinamis }\end{array}$ & 0,058 \\
\hline Gaya berat air & 3,975 & & & Gaya berat air & 3,975 & $\begin{array}{l}\text { Gaya tekan } \\
\text { sedimen }\end{array}$ & 0,533 \\
\hline \multirow[t]{2}{*}{$\begin{array}{l}\text { Gaya berat } \\
\text { sedimen }\end{array}$} & 10,01 & & & $\begin{array}{l}\text { Gaya berat } \\
\text { sedimen }\end{array}$ & 10,01 & $\begin{array}{l}\text { Gempa } \\
\text { horizontal }\end{array}$ & 0,515 \\
\hline & & & & Gempa vertikal & 0,237 & & \\
\hline $\boldsymbol{\Sigma} \mathrm{V}$ & 16,791 & $\boldsymbol{\Sigma} \mathrm{H}$ & 2,027 & $\boldsymbol{\Sigma} \mathrm{V}$ & 17,028 & $\boldsymbol{\Sigma} \mathrm{H}$ & 2,60 \\
\hline
\end{tabular}

Sumber: Hasil perbitungan 


\section{Stabilitas terhadap geser}

$$
\mathrm{SF}=\frac{C \cdot L+F \Sigma V}{\Sigma H}
$$

Berdasarkan perhitungan sebelumnya, didapat data-data sebagai berikut:

- $\quad C=$ Kohesi pasir $=4,0$

- $\quad \mathrm{L}=$ Panjang groundsill $=2,31 \mathrm{~m}$

- $\quad \mathrm{F}=$ Koefisien geser $=0,3$

- $\boldsymbol{\Sigma} \mathrm{V}$ dan $\boldsymbol{\Sigma} \mathrm{H}$ dari Tabel 4 dan 6 untuk kondisi air normal dan Tabel 5 dan 7 untuk kondisi air banjir.

- Kondisi air normal.

a. Tanpa Gempa.

$$
\begin{aligned}
\mathrm{SF} & =\frac{C . L+F \Sigma V}{\Sigma H} \\
= & \frac{(4,0 \times 2,31)+(0,3 \times 5,984)}{0,976} \\
& =11,30>1,5 \text { (aman) }
\end{aligned}
$$

b. Dengan Gempa.

$$
\begin{aligned}
\text { SF } & =\frac{C . L+F \Sigma V}{\Sigma H} \\
= & \frac{(4,0 \times 2,31)+(0,3 \times 6,182)}{2,6} \\
& =4,267>1,2 \text { (aman })
\end{aligned}
$$

- Kondisi air banjir.

a. Tanpa Gempa.

$$
\begin{aligned}
\mathrm{SF} & =\frac{C \cdot L+F \Sigma V}{\Sigma H} \\
= & \frac{(4,0 \times 2,31)+(0,3 \times 7,201)}{1,695} \\
& =6,726>1,5 \text { (Aman) }
\end{aligned}
$$

b. Dengan Gempa.

$$
\begin{aligned}
\mathrm{SF} & =\frac{C . L+F \Sigma V}{\Sigma H} \\
= & \frac{(4,0 \times 2,31)+(0,3 \times 7,399)}{1,979} \\
& =5,79>1,2 \text { (Aman) }
\end{aligned}
$$

\section{Stabilitas terbadap daya dukung tanah}

Tanah sekitar pondasi harus mampu menahan beban ultimate yang dihasilkan oleh tubuh groundsill.

Pemeriksaan eksentrisitas (e)

$$
\mathrm{e}=\left|\frac{\Sigma M}{\Sigma V}-\frac{B}{2}\right|<\frac{1}{6} B
$$

Syarat keamanan:

$$
\mathrm{q}_{\mathrm{u}}=\frac{\Sigma V}{B}\left|1 \pm \frac{6 E}{B}\right|<\mathrm{q}_{\mathrm{ul}}
$$

Menghitung daya dukung tanah $\left(\mathrm{q}_{\text {ult }}\right)$ dengan menggunakan rumus

$$
\begin{aligned}
\mathrm{q}_{\text {ult }}= & \left(1,3 \times C \times \mathrm{N}_{\mathrm{C}}\right)+(\gamma \times \mathrm{D} f \times \mathrm{Nq})+( \\
& \left.0,4 \times \mathrm{B} \times \mathrm{N}_{\gamma}\right)
\end{aligned}
$$

Berdasarkan hasil perencanaan dimensi groundsill didapat data-data sebagai berikut:

- $\quad \mathrm{D} f=$ kedalaman groundsill $=0,5 \mathrm{~m}$

- $\quad B=$ lebar groundsill $=4,61 \mathrm{~m}$

Untuk tanah jenis pasir lepas dengan

$\Theta=30^{\circ}$ didapat nilai koefisien :

$\mathrm{N}_{\mathrm{C}}=37,2 ; \mathrm{Nq}=22,5 ; \mathrm{N}_{\gamma}=20,0 ; \gamma=1,9$

$\mathrm{t} / \mathrm{m}^{3}$, maka :

$$
\begin{aligned}
& \text { qult }=(0,5 \times 0 \times 37,2)+(1,9 \times 0,5 \times, 22,5) \\
& +(0,4 \times 2,31 \times 20,0) \\
& =39,855 \mathrm{t} / \mathrm{m}^{3}
\end{aligned}
$$

Daya dukung tanah yang diijinkan :

$$
\overline{q_{u l t}}=\frac{\text { qult }}{S F}=\frac{39,855}{5,79}=6,88 \mathrm{t} / \mathrm{m}^{3}
$$

- Kondisi air normal.

a. Tanpa Gempa.

$$
\begin{aligned}
\mathrm{e} & =\left|\frac{(19,178-1,093)}{5,984}-\frac{24,61}{2}\right|<\frac{1}{6} \times 4,61 \\
& =0.717<0,768 \\
\mathrm{q}_{\mathrm{u}} & =\frac{5,984}{4,61}\left[1 \pm \frac{(6 \times 0,717)}{4,61}\right]<\overline{q_{u l t}}=6,88 \\
\mathrm{q}_{\max } & =2,509 \mathrm{t} / \mathrm{m}^{2}<\overline{q_{u l t}}=6,88 \mathrm{t} / \mathrm{m}^{2} \\
\mathrm{q}_{\text {min }} & =0,086 \mathrm{t} / \mathrm{m}^{2}<\overline{q_{u l t}}=6,88 \mathrm{t} / \mathrm{m}^{2}
\end{aligned}
$$

b. Dengan Gempa.

$$
\begin{aligned}
\mathrm{e} & =\left|\frac{(18,415-1,666)}{6,182}-\frac{4,61}{2}\right|<\frac{1}{6} \times 4,61 \\
& =0.404<0,768 \\
\mathrm{q}_{\mathrm{u}} & =\frac{6,182}{4,61}\left[1 \pm \frac{(6 \times 0,404)}{4,61}\right]<\overline{q_{u l t}}=6,88 \\
\mathrm{q}_{\max } & =2,046 \mathrm{t} / \mathrm{m}^{2}<\overline{q_{u l t}}=6,88 \mathrm{t} / \mathrm{m}^{2} \\
\mathrm{q}_{\text {min }} & =0,635 \mathrm{t} / \mathrm{m}^{2}<\overline{q_{u l t}}=6,88 \mathrm{t} / \mathrm{m}^{2}
\end{aligned}
$$

- Kondisi air banjir.

a. Tanpa Gempa.

$$
\begin{aligned}
\mathrm{e} & =\left|\frac{(16,791-2,027)}{7,201}-\frac{4,61}{2}\right|<\frac{1}{6} \times 4,61 \\
& =-0,254<0,768 \\
\mathrm{q}_{u} & =\frac{7,201}{4,61}\left[1 \pm \frac{(6 x-0,254)}{4,61}\right]<\overline{q_{u l t}}=6,88
\end{aligned}
$$




$$
\begin{aligned}
& \mathrm{q}_{\text {max }}=1,046 \mathrm{t} / \mathrm{m}^{2}<\overline{q_{u l t}}=6,88 \mathrm{t} / \mathrm{m}^{2} \\
& \mathrm{q}_{\text {min }}=2,078 \mathrm{t} / \mathrm{m}^{2}<\overline{q_{u l t}}=6,88 \mathrm{t} / \mathrm{m}^{2}
\end{aligned}
$$

b. Dengan Gempa.

$$
\begin{aligned}
& \mathrm{e}=\left|\frac{(17,028-2,60)}{7,399}-\frac{4,61}{2}\right|<\frac{1}{6} \times 4,61 \\
& =-0,355<0,768 \\
& \mathrm{q}_{\mathrm{u}}=\frac{7,399}{4,61}\left[1 \pm \frac{(6 x-0,355)}{4,61}\right]<\overline{q_{u l t}}=6,88 \\
& \mathrm{q}_{\max }=0,905 \mathrm{t} / \mathrm{m}^{2}<\overline{q_{u l t}}=6,88 \mathrm{t} / \mathrm{m}^{2} \\
& \mathrm{q}_{\min }=0,741 \mathrm{t} / \mathrm{m}^{2}<\overline{q_{u l t}}=6,88 \mathrm{t} / \mathrm{m}^{2}
\end{aligned}
$$

\section{Kesimpulan}

1. Penggerusan di hilir Bendung Waikomo terjadi karena perilaku aliran yang terjadi adalah super kritis setelah melalui mercu bendung sehingga material di hilir tidak mampu menahan pukulan aliran, disisi lain karena adanya kegiatan penambangan material galian $\mathrm{C}$ oleh masyarakat setempat yang tidak memperhatikan peraturan yang ada.

2. Bangunan groundsill direncanakan di hilir bendung dengan menggunakan pasangan batu kali dengan dimensi sebagai berikut:
a. Jarak dari bendung $\quad=75 \mathrm{~m}$
b. Lebar
$=30 \mathrm{~m}$
c. Panjang
$=4,61 \mathrm{~m}$
d. Tinggi
$=1,5 \mathrm{~m}$
e. Kedalaman pondasi $=0,5 \mathrm{~m}$
f. Tipe peredam energi kolam olakan type III

3. Bangunan groundsill yang direncanakan aman terhadap kontrol guling, geser dan daya dukung tanah yang ditunjukkan dengan semua nilai $\mathrm{SF}>1,5$.

\section{Daftar Pustaka}

[1]. Chow, V T. 1997. Hidrolika Saluran Terbuka. Erlangga. Jakarta.
[2]. Harto, S. 1983. Mengenal Dasar Hidrolika Terapan. Kanisius. Jakarta

[3]. Mawardi, E. 2010. Desain Hidraulik Bendung tetap Untuk Irigasi Teknis. Alfabeta. Bandung.

[4]. Soemarto, C D. 1986. Hidrologi Teknik. Gramedia. Jakarta.

[5]. Sosrodarsono, S. 1984. Perbaikan dan Pengaturan Sungai. Pradnya Paramita. Jakarta.

[6]. Sosrodarsono, S. 1984. Bendungan Type Urugan. Pradnya Paramita. Jakarta.

[7]. Subarkah, I. 1980. Hidrologi Untuk Perencanaan Bangunan Air. Kanisius. Bandung.

[8]. Tahir, M. 2005. Studi Perencanaan Groundsill Untuk Menangani Penurunan Elevasi Dasar Sungai Brantas Di Kabupaten Jombang. Skripsi. Tidak Diterbitkan. ITN Malang. 